\title{
Sweep enhancers for oil recovery
}

\author{
Joris van Santvoort ${ }^{1}$ (i) Michael Golombok $^{1,2}$
}

Received: 24 March 2015/Accepted: 17 October 2015/Published online: 30 October 2015

(C) The Author(s) 2015. This article is published with open access at Springerlink.com

\begin{abstract}
The use of viscoelastic sweep improvers to overcome injected fluid diversion is assessed at the low pressure gradients associated with secondary oil production. The flow evolves from Newtonian to non-Newtonian behavior with increasing pressure gradient. Additive concentration determines this transition and controls the effectiveness of selective retardation. This is demonstrated in an experimental simulation of parallel flow in two core samples of different permeabilities. Even at pressure gradients lower than $1.0 \mathrm{bar} / \mathrm{m}$ channeling can effectively be reduced and early water breakthrough delayed. This has the potential to greatly increase ultimate oil recovery.
\end{abstract}

Keywords Enhanced oil recovery · Viscoelastic surfactants $\cdot$ Channeling

\section{List of symbols}

$\begin{array}{ll}L & \text { Length core }(\mathrm{m}) \\ n & \text { Layer number } \\ \Delta P & \text { Pressure drop }(\mathrm{Pa}) \\ R & \text { Flow rate ratio } \\ u & \text { Darcy velocity }(\mathrm{m} / \mathrm{s}) \\ \Delta x & \text { Length porous media }(\mathrm{m}) \\ x & \text { Position flow front }(\mathrm{m}) \\ \gamma & \text { Shear rate }(1 / \mathrm{s})\end{array}$

\section{Joris van Santvoort}

j.f.m.v.santvoort@tue.nl

Michael Golombok

Michael.Golombok@shell.com

1 Technische Universiteit Eindhoven, 5612 AZ Eindhoven, The Netherlands

2 Shell Global Solutions International B.V., $1031 \mathrm{HW}$ Amsterdam, The Netherlands

$\begin{array}{ll}\eta & \text { Sweep efficiency } \\ \kappa & \text { Permeability }\left(\mathrm{m}^{2}\right) \\ \Lambda & \text { Resistance factor } \\ \mu & \text { Viscosity (Pa s) } \\ \text { Subscripts } \\ 0 & \text { Base fluid } \\ \text { app } & \text { Macroscopic/apparent } \\ b & \text { Breakthrough layer } \\ c & \text { Critical } \\ f & \text { Flow rate } \\ \text { hi } & \text { High permeability } \\ \text { lo } & \text { Low permeability } \\ n & \text { Layer } n\end{array}$

\section{Introduction}

During secondary oil recovery water is injected into an oil reservoir to artificially increase reservoir pressure and maintain production. On average only about one-third of the original oil in place (OOIP) is recovered after water flooding (Al-Mjeni et al. 2011). Four factors are responsible for this poor recovery efficiency. On a microscopic scale wettability effects cause oil to be trapped inside the pores of the reservoir rock. Furthermore, viscous instabilities at the oil/water interface lead to viscous fingering. These two microscopic phenomena are typically targeted by classical enhanced oil recovery (EOR) techniques. The main restrictions, however, arise on the macroscopic scale where reservoir heterogeneity decreases recovery effectiveness. Displacing fluid bypasses large sections of oil through so called 'thief zones' which consist of high permeability porous matrix layers or naturally formed fractures. Nearby oil-rich low permeability zones are bypassed

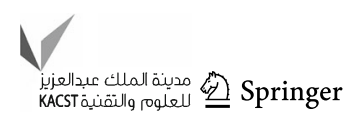


and the oil is stranded. This effect not only decreases the recovery potential of a reservoir, it also increases the water-cut at the production well.

Polymeric fluids can be used to overcome preferential flow problems (see below). These fluids have an enhanced viscosity which reduces the mobility factor (Degré and Morvan 2012). The shear thinning nature of these fluids is favorable for injectivity but it can increase the unfavorable effect of preferential flow through high permeability zones (AlSofi et al. 2009; Delshad et al. 2008; Silva et al. 2012).

By contrast, viscoelastic surfactants (VES) display shear thickening under reservoir conditions and shear thinning during injection. Previous research showed that these materials can reduce the flow through high permeability zones by selectively altering the viscosity (Golombok and van der Wijst 2013; Smeets and Golombok 2010). As a result, less displacing fluid will be lost through 'thief zones', increasing the overall effectiveness of the recovery process. Highly heterogeneous and/or fractured reservoirs can thus benefit from this technology allowing a more efficient recovery process. This technology has only been demonstrated for relatively large pressure gradients (10-100 bar/m). This was for ease of demonstration but considerably higher than those used for industrial application. The average pressure gradient is usually around $1.0 \mathrm{bar} / \mathrm{m}$. However, due to a disproportionately large pressure loss at the injector the actual pressure gradient in the reservoir is usually significantly lower. The use of viscosifying surfactants at these low pressure gradients $(0.1-1.0 \mathrm{bar} / \mathrm{m})$ is examined in this paper.

The background on the use of VES fluids and other nonNewtonian fluids for improved water flooding is discussed in "Background" section. A novel experimental setup designed to test the use of VES fluids for improved sweep efficiency is described in "Experimental" section. "Results and discussion" section presents and discusses the results.

\section{Background}

\section{Reservoir flow}

Flow through fractures and porous zones is governed by Darcy's law for Newtonian fluids (Bear 1972):

$u=\frac{\kappa}{\mu} \frac{\Delta P}{L}$

Here, $u$ is the Darcy velocity, $\kappa$ the permeability, $\mu$ the viscosity, and $\Delta P$ the pressure drop over the length of a porous media $L$. A reservoir inevitably contains regions with different permeabilities. Flow advances ahead of the average position in regions of higher permeability. The effect of this preferential flow can be evaluated by comparing the velocity in each streak with the velocity in the least permeable layer. This results in a dimensionless factor; the ratio of the flow velocities in zones with high and low permeability $u_{\mathrm{hi}}$ and $u_{\mathrm{lo}}$ at equal pressure gradient (Reuvers and Golombok 2008):

$R_{\mathrm{f}}=\left(\frac{u_{\mathrm{hi}}}{u_{\mathrm{lo}}}\right)_{\Delta P / L}=\left(\frac{\kappa_{\mathrm{hi}}}{\kappa_{\mathrm{lo}}} \frac{\mu_{\mathrm{lo}}}{\mu_{\mathrm{hi}}}\right)_{\Delta P / L}$

In the case of Newtonian flow, the flow ratio $R_{\mathrm{f}}$ is equal to the ratio of permeability $\kappa_{\mathrm{hi}}$ and $\kappa_{\mathrm{lo}}$ since viscosity $\mu_{\mathrm{lo}}$ and $\mu_{\mathrm{hi}}$ are equal. In order to change this ratio non-Newtonian fluids can be used with a viscosity dependent on shear rate, and thus, indirectly on permeability.

\section{Non-Newtonian reservoir flow}

Non-Newtonian polymer flooding aims to increase the viscosity of the displacing phase thereby decreasing the mobility factor and reducing the formation of viscous fingers (Wei et al. 2014). However, in theory polymer solutions have unfavorable rheological properties concerning preferential flow as occurs during channeling (AlSofi et al. 2009). Shear thinning leads to a viscosity decrease in high permeability zones due to a high local shear rate. The disparity of flow velocity between different permeable layers will increase as a result of the difference in viscosity. This will enhance the effect of preferential flow $\left(R_{\mathrm{f}}\right.$ increases, Eq. 2), decreasing sweep efficiency and increasing the required injected pore volume (Delshad et al. 2008).

In 1980 it was suggested that a shear thickener fluid could be employed to overcome preferential flow in heterogeneous reservoirs (Jones 1980). In a reservoir, where the displacing fluid in high permeability regions is exposed to a high shear rate, the local fluid viscosity increases. Equation 2 shows that selective fluid thickening effectively reduces the difference in flow velocity between zones, leading to an improved sweep efficiency (Delshad et al. 2008; Jones 1980). The downside to a purely shear thickening fluid would be a large increase in viscosity at the injector which decreases the injection rate (Reuvers and Golombok 2009). The solution to this problem is a fluid which shows a non-monotonic shear response. Shear thickening at low to medium shear rates improves sweep efficiency. Shear thinning at high shear rate overcomes injection problems. This desired non-monotonic behavior has been found in dilute VES (viscoelastic surfactants) and can be seen in Fig. 1 (Hartmann and Cressely 1996; 1997; Vasudevan et al. 2010).

\section{Viscoelastic surfactants}

Some solutions of cationic surfactants spontaneously aggregate to form polymer-like flexible worm-like 


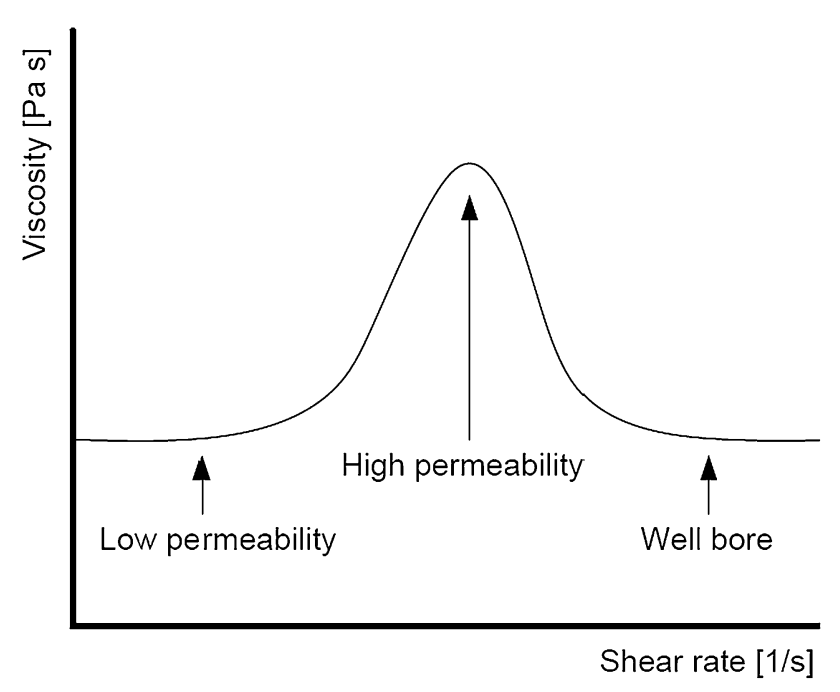

Fig. 1 Non-monotonic, shear thickening/shear thinning response of viscoelastic surfactant

micelles. The critical surfactant concentration at which these worm-like micelles are formed can be decreased by adding complex salts (Hartmann and Cressely 1996). The shear thickening behavior is a consequence of the formation of structures arising from the shear-induced motion of the micelles (Vasudevan et al. 2008). Once shear rates become too high the formed structures disband decreasing viscosity, i.e., shear thinning.

Complex flows of worm-like micelles have been studied by looking at the flow of VES materials through periodic arrays of cylinders (Moss and Rothstein 2009). It was found that for a purely shear thinning solution the pressure drop over an array of cylinders initially decreases with increasing flow rate which is in accordance with the shear thinning nature. However, as flow rates become large, elongational effects begin to dominate over shear effects increasing viscosity.

A few studies specifically mention the viscosity modifying ability of viscoelastic surfactants in complex flows such as porous media (Ezrahi et al. 2007). A solution containing a cationic and anionic surfactant which has nonmonotonic rheological behavior was studied when flowing through a cylinder with mono-disperse glass spheres (Rojas et al. 2008, 2009). It was found that the elongational component of the flow promotes further interaction between worm-like micelles resulting in an enhanced apparent viscosity. This apparent viscosity appeared to be larger than the maximum viscosity found in a rheometer and was attributed to the elongational component of the flow. Pure elongational flow experiments support this claim showing that the elongational component can have a much higher apparent viscosity (Hu et al. 1994).

Application wise the use of VES materials for preferential flow reduction has been investigated by Golombok and van der Wijst (2013). They use surfactant CTAB (cetyl trimethyl ammonium bromide) and complex salt NaSal (sodium salicylate) to demonstrate reduced channeling in single phase flow at high pressure gradient (10-100 bar $/ \mathrm{m})$.

\section{Experimental}

\section{Materials}

Surfactant CTAB ( $>99.0 \%$ purity) and complex salt NaSal ( $>99.5 \%$ purity) were purchased from Sigma Aldrich. CTAB is a cationic surfactant with a critical micelle concentration of $0.9 \mathrm{mM}$ which is significantly lowered when adding complex salt NaSal (Moss and Rothstein 2009). Equimolar concentrations (1.0/1.0, 1.5/1.5, and 2.0/ $2.0 \mathrm{mM}$ ) are dissolved in $3 \mathrm{wt} \% \mathrm{NaCl}$ demineralized water (brine) and stirred until the solution was clear. This is chosen as representative of sea water and is further not a variable in this application demonstration. The solution was kept at room temperature for at least $24 \mathrm{~h}$ to ensure that all chemicals were fully dissolved and equilibrium was reached. To validate the non-monotonic response and characterize the properties of different solutions, a rheometer (Anton Paar MCR302) was used.

The porous samples consist of borosilicate beads sintered together into cylindrical cores. For accurate measurements in the low pressure gradient regime the length of the cores is set at $300 \mathrm{~mm}$ with a diameter of $50.8 \mathrm{~mm}$. Cores with different properties are produced by ROBU GlasfilterGeraete GmbH (Table 1). Sintered glass cores are used in this study because they have a more homogeneous permeability distribution compared to rock cores as can be seen in the radial CT-scan of one of the cores (Fig. 2). Porosity is determined using a CT-scan of the core and "Procedure" section explains how to brine permeability was found.

\section{Dual core single phase flow setup}

To test the selective viscosifying behavior of VES fluids in a heterogeneous reservoir a parallel core flow experiment was designed. Two sintered glass cores, with a rubber sleeve wrapped around each, are placed inside two core holders. The core holder and the sleeve are radially

Table 1 Sintered glass core properties

\begin{tabular}{lccl}
\hline Core name & $\begin{array}{l}\text { Pore size } \\
(\mu \mathrm{m})\end{array}$ & $\begin{array}{l}\text { Brine permeability } \\
(\mathrm{mD})\end{array}$ & $\begin{array}{l}\text { Porosity } \\
(\%)\end{array}$ \\
\hline $\mathrm{A}$ & $2-6$ & 160 & 48 \\
$\mathrm{~B}$ & $6-10$ & 700 & 45 \\
$\mathrm{C}$ & $10-40$ & 2500 & 42 \\
$\mathrm{D}$ & $10-40$ & 4400 & 42 \\
\hline & & & \\
& & &
\end{tabular}




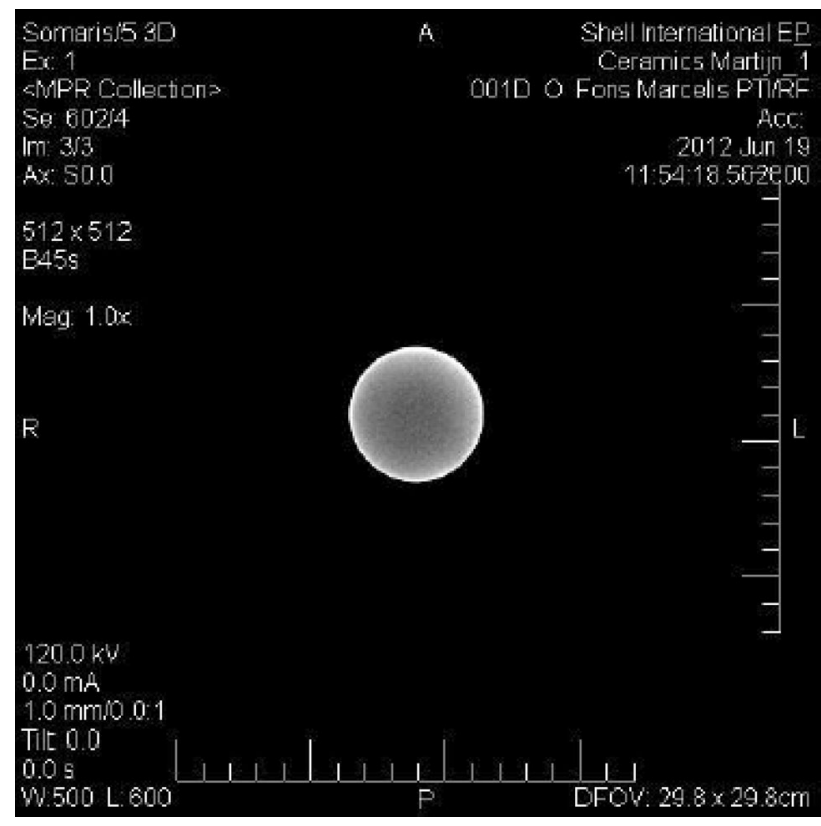

Fig. 2 Radial CT-scan of sintered glass core

pressurized inwards with compressed air to force a tight seal to ensure axial flow. Brine permeabilities of the cores range from 160 to $4400 \mathrm{mD}$. A parallel flow configuration allows for direct comparison of the viscosity difference as a result of varying permeability between two cores at equal pressure drop. The cores are positioned vertically such that air traps do not form.

Figure 3 shows the experimental setup. A dual piston Quizix pump (QX $6000 \mathrm{HC}$ pump; accuracy $0.25 \%$; range $0.001-50 \mathrm{ml} / \mathrm{min}$ ) simultaneously forces the viscoelastic fluid through the two cores. The pressure gradient over both cores is measured by two differential pressure transducers (Rosemount 3051CD 4; accuracy $0.1 \%$; range -20.5 to +20.5 bar) and the flow rate is measured by constantly monitoring the effluent weight using scales (Sartorius SECURA5102-1S; accuracy $1 \%$; range $12-5100 \mathrm{~g}$ ). The setup is placed inside a climate chamber (Memmert IPP260; accuracy $0.1{ }^{\circ} \mathrm{C}$; range $0-70{ }^{\circ} \mathrm{C}$ ) with constant temperature of $22{ }^{\circ} \mathrm{C}$. (Actual reservoir temperatures are much higher than $22{ }^{\circ} \mathrm{C}$, but the initial goal of this paper is to demonstrate the principle of selective viscosifying at easily controllable conditions.)

\section{Procedure}

Before each measurement the cores are placed in an oven of $250{ }^{\circ} \mathrm{C}$ for at least $12 \mathrm{~h}$ to evaporate all the fluid inside the pores left from previous experiments. After cooling down to room temperature they are placed inside the core holders and flushed with $\mathrm{CO}_{2}$ to force air out. A permeability check with brine is done to check whether the cores were cleaned properly and if all the air was removed (Table 1). To determine the permeability, the pressure drop $(\Delta P)$ over each core is measured for five different brine flow rates. In combination with the known dimensions of the core and the constant viscosity of brine, Eq. 1 can be used to calculate the permeability for each core. This step is repeated before each experiment to make sure that previous experiments do not affect the current measurement. The accuracy of this procedure is the sum of the errors of all the variables in Eq. 1 and equal to $3.95 \%$.

The viscoelastic surfactant solution is then pumped into the cores at low flow rates until both cores have been flushed with 2 pore volumes (PV). Low flow rates are

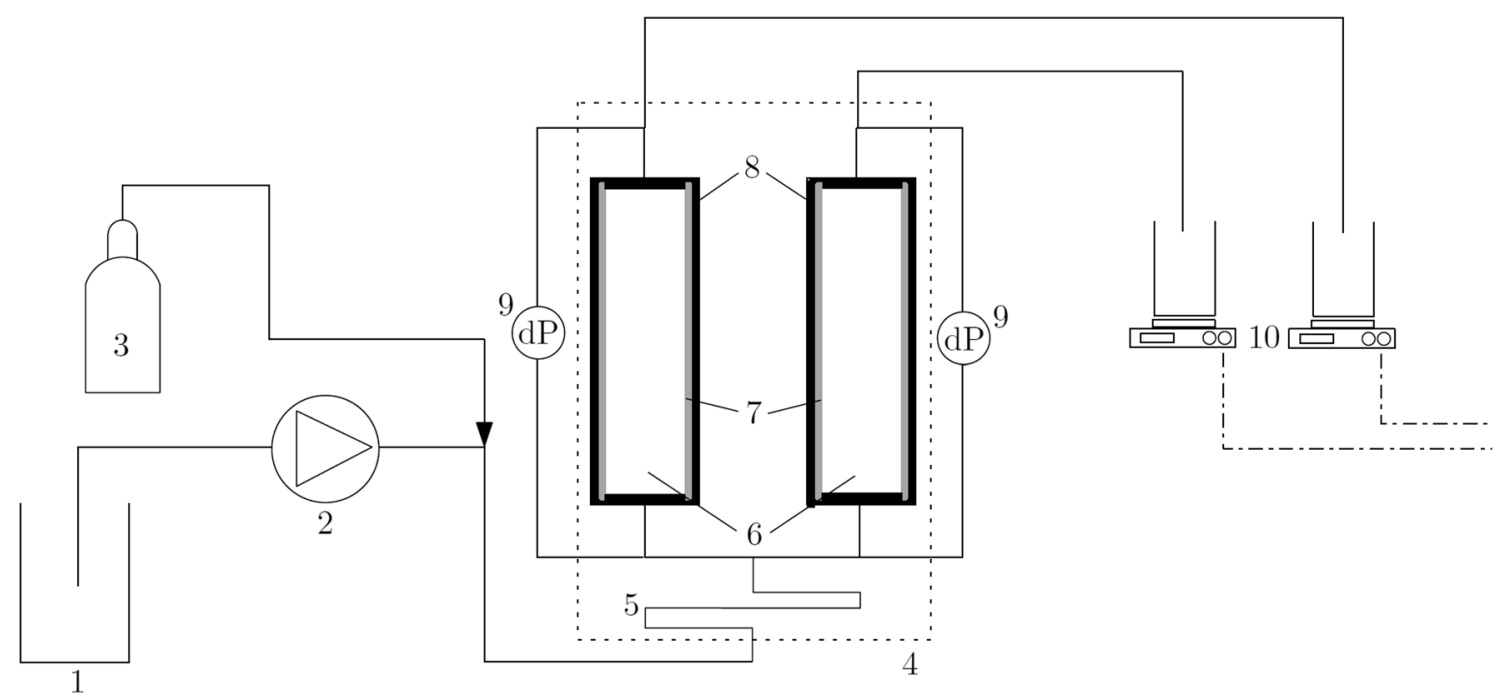

Fig. 3 Overview of dual core flow setup: (1) fluid supply, (2) dual piston Quizix pump, (3) $\mathrm{CO}_{2}$ supply, (4) climate chamber, (5) heat exchanger, (6) sintered glass core, (7) rubber sleeve, (8) stainless steel core holder, (9) differential pressure transducer, (10) scales 
required to prevent the premature formation of an irreversible flow-induced structured phase (FISP) (Vasudevan et al. 2010). These permanent FISP could then influence a measurement point at low flow rate where they normally would not be present. In order to avoid this, a low saturation flow rate is required.

Once the cores have been saturated the pump is set to stepwise increase the flow rate $(0.10-40 \mathrm{ml} / \mathrm{min}$ with increasing step sizes from 0.05 to $5 \mathrm{ml} / \mathrm{min}$ ) for a period of $40 \mathrm{~min}$ per measurement point to obtain equilibrium. The applied flow rate results in an equal pressure drop over both cores, which is recorded by the pressure transducers. The flow through both cores is monitored and recorded using the scales. Each experiment is performed twice to ensure reproducibility. After each experiment 2 pore volumes of demineralized water is injected to flush out the viscoelastic solutions after which the cores are placed in the oven to dry-out (Spain et al. 2009).

\section{Results and discussion}

\section{Simple shear}

The rheological response of a solution of $\mathrm{CTAB} / \mathrm{NaSal}$ in demineralized water in a simple shear geometry has been extensively researched (Hartmann and Cressely 1996; Vasudevan et al. 2008; Hu et al. 1994). However, for a reservoir flooding application the base fluid is usually seawater, especially in offshore applications where this is abundantly available. Seawater on average contains about $3 \mathrm{wt} \%$ of simple salt and this concentration is therefore chosen as the standard.

The shear response of three dilute solutions with equimolar $\mathrm{CTAB} / \mathrm{NaSal}$ concentrations in brine can be seen in Fig. 4. Several aspects of CTAB/NaSal in brine under Couette shear can be noted. At low shear rates all solutions show Newtonian behavior with a constant zero shear viscosity which is slightly enhanced compared to the viscosity of the base fluid brine. As shear rate increases, a critical shear rate $\left(\gamma_{c}\right)$ is reached which is the onset of shear thickening. After this point the viscosity increases by the formation of shear-induced structures (SIS) until a maximum viscosity is reached. Once this maximum viscosity is reached, shear thinning occurs arising from the degradation of the shear-induced structures. Increasing the equimolar concentration of $\mathrm{CTAB} / \mathrm{NaSal}$ decreases the critical shear rate and increases the magnitude of shear thickening.

\section{Dual core flow}

Figure 5 shows the flow rate against pressure gradient for an equimolar concentration of $1.5 \mathrm{mM} \mathrm{CTAB} / \mathrm{NaSal}$ in

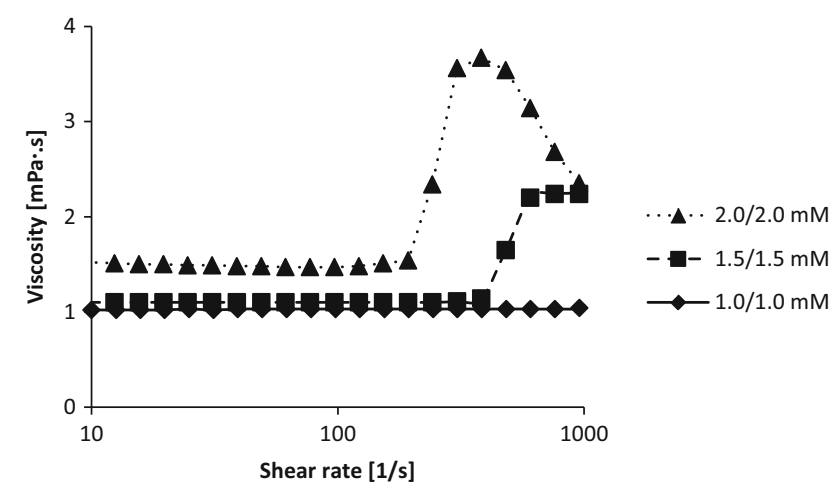

Fig. 4 Simple shear rheology of different equimolar concentrations of $\mathrm{CTAB} / \mathrm{NaSal}$ in $3 \mathrm{wt} \% \mathrm{NaCl}$ demineralized water at $22{ }^{\circ} \mathrm{C}$

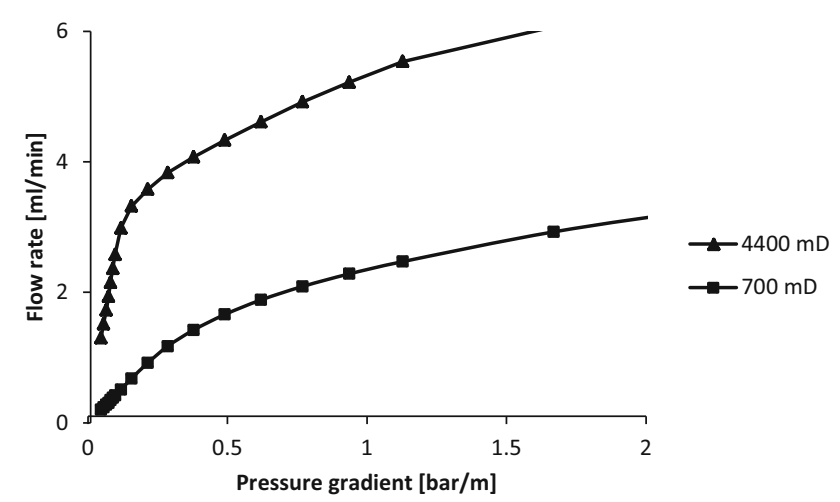

Fig. 5 Flow rate plotted against pressure gradient for two cores (4400 and $700 \mathrm{mD}$ ) using a $1.5 / 1.5 \mathrm{mM}$ solution of CTAB/NaSal in brine at $22{ }^{\circ} \mathrm{C}$

brine for two cores with permeabilities of 700 and $4400 \mathrm{mD}$. At low pressure gradients $(\Delta P / L<0.1 \mathrm{bar} / \mathrm{m})$ both graphs show a linear relationship between pressure gradient and flow rate but with a different slope. As pressure gradient is increased the graphs depart from this linear behavior. The slope of the graph of the $4400 \mathrm{mD}$ core relatively decreases more than the slope of the $700 \mathrm{mD}$ core indicating a more reduced flow in the high permeability core. This suggests that the viscosity increase, caused by formation of SIS, is permeability dependent.

Figure 6 shows that for VES at the low pressure gradient regime $(\Delta P / L<0.1 \mathrm{bar} / \mathrm{m})$ the flow rate ratio $R_{\mathrm{f}}(\mathrm{Eq} .2)$ between the high and low permeability core is constant. This constant value is approximately identical to the ratio when using brine $\left(R_{\mathrm{f}} \approx 6\right)$. This indicates that fluid viscosity is equal in both cores and that the flow rate contrast is proportional to the difference in permeability. When the pressure gradient increases $(\Delta P / L>0.1 \mathrm{bar} / \mathrm{m})$ a decrease of $R_{\mathrm{f}}$ is found. i.e., there is selective retardation in the high permeability core. At a pressure gradient of $1 \mathrm{bar} / \mathrm{m}$ the difference in flow rate has been reduced significantly from 


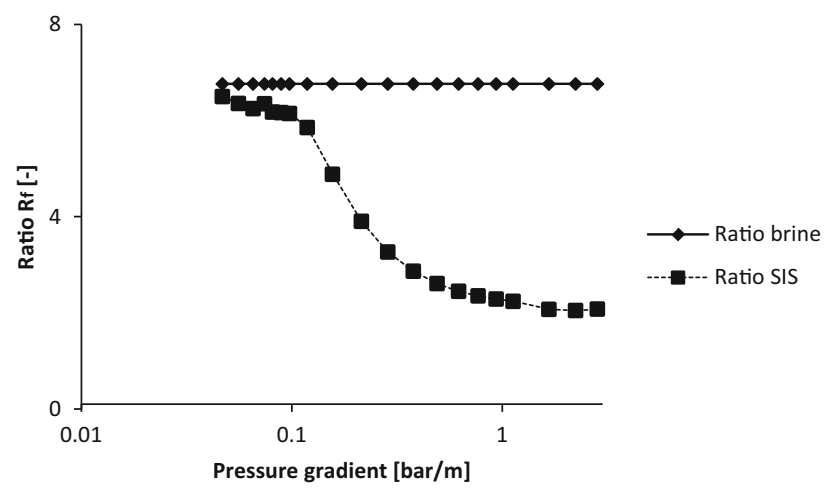

Fig. 6 Ratio of flow rates between 4400 and $700 \mathrm{mD}$ core plotted for brine (diamonds) and a $1.5 / 1.5 \mathrm{mM}$ solution of CTAB/NaSal in brine (squares) against pressure gradient

6 to 2 . This reduction in the difference in flow rates has thus created a more uniform flow through these two different permeable cores.

The effect of selective viscosifying can be investigated by introducing a resistance factor $\Lambda$ (Golombok and van der Wijst 2013; Rojas et al. 2008), which is defined as:

$\Lambda=\frac{\kappa}{\mu_{0} u} \frac{\Delta P}{L}$

Here, $\mu_{0}$ is the viscosity of the base fluid (brine). Figure 7 shows the resistance factor versus pressure gradient obtained using Eq. 3 for four different permeable cores using a single equimolar solution. At low pressure gradient $(\Delta P / L<0.1 \mathrm{bar} / \mathrm{m})$ the resistance factor for all four cores is equal and constant, indicating a Newtonian regime. The resistance factor found here is close to unity, indicating that the apparent viscosity in the porous cores is similar to the viscosity of the base fluid (brine). Increasing the pressure gradient results in a departure from Newtonian behavior and an increase in resistance factor (at $0.1 \mathrm{bar} / \mathrm{m}$ ). From this point on there is also an increasing difference in

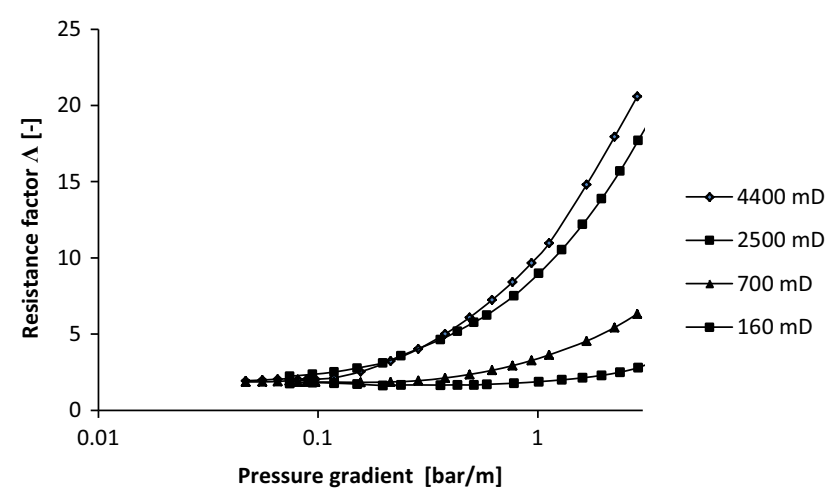

Fig. 7 Resistance factor versus pressure gradient using a $1.5 / 1.5 \mathrm{mM}$ solution of $\mathrm{CTAB} / \mathrm{NaSal}$ in brine for four different cores $(4400,2500$, 700 and $160 \mathrm{mD}$ ) at $22{ }^{\circ} \mathrm{C}$ resistance factor between cores of different permeabilities. The resistance is higher in cores of higher permeability. For a pressure gradient of $1.0 \mathrm{bar} / \mathrm{m}$, the resistance factor of the high permeability core $(4400 \mathrm{mD})$ is over five times higher compared to the low permeability core $(160 \mathrm{mD})$.

In order to compare the shear viscosity with the measured resistance factor, typical shear rates in porous flow can be calculated which are proportional to flow velocity $v$ (Stavland et al. 2010):

$\dot{\gamma}=\frac{4 \cdot \alpha \cdot v}{\sqrt{8 \kappa / \phi}}$

Here, $\alpha$ is equal to 2.5 . Permeability $\kappa$ and porosity $\phi$ belong to the used core and the flow velocity $v$ is set during the experiment. Equivalent shear rates in the porous media calculated using Eq. 4 show that it ranges from 10 to $2000 \mathrm{~s}^{-1}$. Figure 4 shows that for a $1.5 / 1.5 \mathrm{mM}$ solution of $\mathrm{CTAB} / \mathrm{NaSal}$ in brine the maximum shear viscosity in this range is $2.25 \mathrm{mPa}$ s. However, in the core flow experiment (Fig. 7) at $1.0 \mathrm{bar} / \mathrm{m}$ this solution shows an apparent viscosity of approximately $11 \mathrm{mPa}$ s for a $4400 \mathrm{mD}$ core. The apparent viscosity goes up further as pressure gradient is increased. This is caused by the elongation component of the flow in porous media (Smeets and Golombok 2010). The effect appears to be more pronounced in high permeability cores leading to the desired selective viscosifying effect.

\section{Concentration effects}

Figure 8 shows three graphs which represent different equimolar concentrations of $\mathrm{CTAB}$ and $\mathrm{NaSal}$ at a single pressure gradient $(0.5 \mathrm{bar} / \mathrm{m})$. The graphs give the resistance factor resulting from the flow of these solutions through cores of different permeabilities. A higher concentration leads to enhanced apparent viscosity effects in permeable flow. The difference in viscosity between layers of different permeabilities ultimately determines the effectiveness of reducing channeling by means of selective retardation. Therefore, $1.5 / 1.5 \mathrm{mM}$ shows the most promise of the solutions tested, since here the relative difference in resistance factor between low and high permeability is the largest.

Experiments with different equimolar concentrations using a single permeability core of $700 \mathrm{mD}$ are compared in Fig. 9. As the concentration of surfactant and complex salt increase, the flow velocity at which thickening occurs decreases. A 1.0/1.0 mM solution in brine starts thickening at $10 \mathrm{ft} /$ day whereas a $2.0 / 2.0 \mathrm{mM}$ solution in brine starts at $1.0 \mathrm{ft} /$ day. This is in line with the findings from the rheometer which showed that increasing equimolar concentration leads to a decrease in critical shear rate (Fig. 4) which corresponds to a lower flow rate in permeable flow (Eq. 4). 


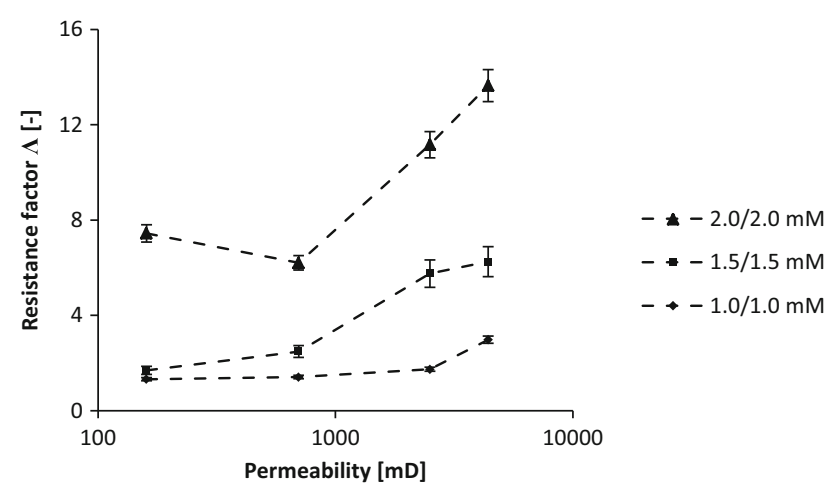

Fig. 8 Resistance factor plotted against permeability at a constant pressure gradient of $0.5 \mathrm{bar} / \mathrm{m}$ at $22{ }^{\circ} \mathrm{C}$ for three different equimolar solutions of $\mathrm{CTAB} / \mathrm{NaSal}$ in brine

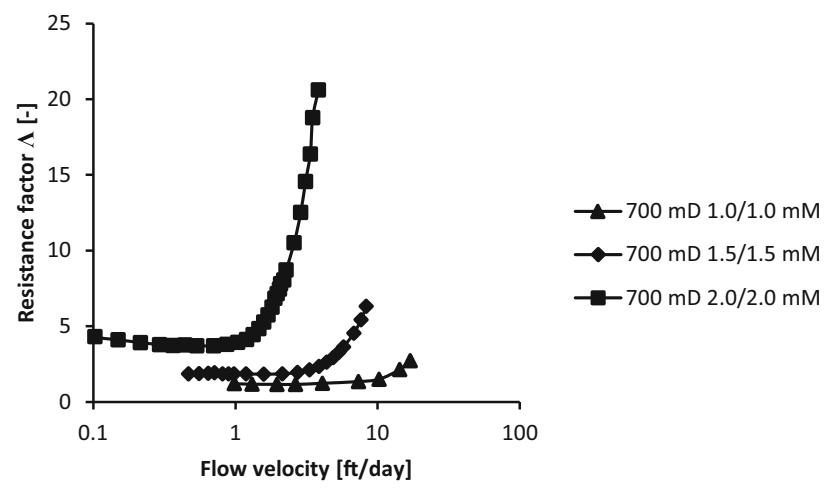

Fig. 9 Resistance factor plotted against flow rate at $22{ }^{\circ} \mathrm{C}$ for three different equimolar solutions of $\mathrm{CTAB} / \mathrm{NaSal}$ in brine using a single core $(700 \mathrm{mD})$

\section{Impact on recovery}

To demonstrate the added value of VES materials as a displacement fluid, consider a hypothetical seven layered heterogeneous reservoir (Fig. 10). The layers have permeabilities that correspond to the cores which were used during the experiments. The results obtained during the experiments are imposed on this hypothetical reservoir which has been arranged to have a middle section with highest permeability - arbitrary in the case as there is no communication between layers in this model. At equal pressure drop early water breakthrough will occur in this middle layer with the highest permeability $\kappa_{b}$ and a corresponding VES viscosity $\mu_{\mathrm{app}, b}$. Sweep efficiency $\eta_{b}$ at breakthrough is evaluated by adding the relative position of the flow fronts $x_{n} / x_{b}$ from each layer $n$ :

$\eta_{b}=\sum_{i=1}^{n} \frac{x_{n}}{x_{b}}=\sum_{i=1}^{n} \frac{\kappa_{n} \cdot \mu_{\mathrm{app}, b}}{\kappa_{b} \cdot \mu_{\mathrm{app}, n}}$

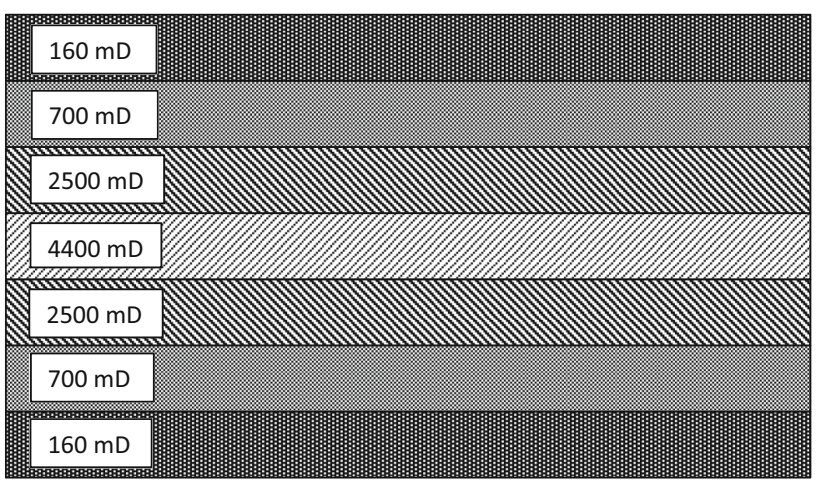

Fig. 10 Schematic overview of a horizontal heterogeneous reservoir consisting of seven layers with different permeabilities

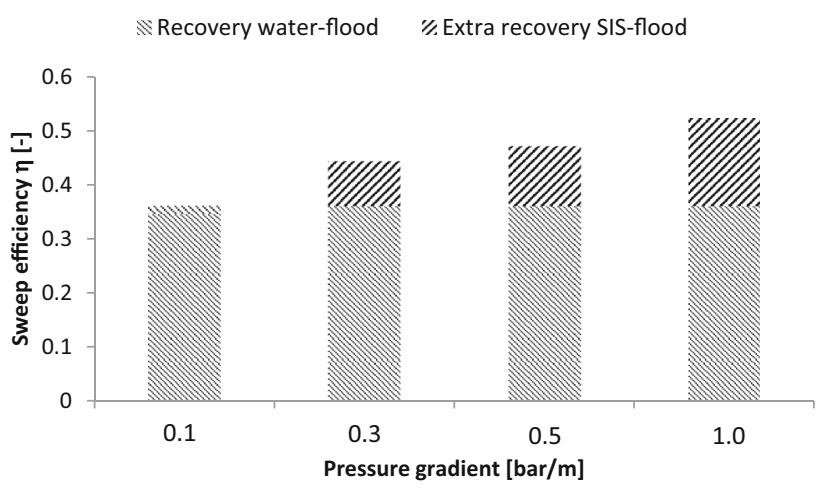

Fig. 11 Added sweep efficiency when flooding with $1.5 \mathrm{mM} \mathrm{CTAB/}$ $\mathrm{NaSal}$ solution in brine through a heterogeneous reservoir consisting of 7 layers $(4400,2500,700$, and $160 \mathrm{mD}$ ) at four different pressure gradients

Here, $\kappa_{n}$ is the permeability of layer $n$ with VES viscosity $\mu_{\text {app }, n}$. This equation assumes a one phase situation with no oil present in the reservoir and a piston like fluid displacement through each layer. (As mentioned above, for the purpose of demonstration, communication between layers is ignored.) Microscopic effects are not included and only the macroscopic behavior is considered.

The result can be seen in Fig. 11 for different pressure gradients using a $1.5 \mathrm{mM} \mathrm{CTAB} / \mathrm{NaSal}$ solution in brine. The thin diagonal lines represent the sweep efficiency when flooding with water. The thick diagonal lines represent the added value from flooding with a SIS-solution as an alternative to water. At $0.1 \mathrm{bar} / \mathrm{m}$ there is no significant influence on sweep efficiency because as previously stated the solution behaves as a Newtonian fluid. Increasing the pressure gradient, which boosts the production rate, leads to a sweep efficiency increase of up to $16 \%$, increasing potential recovery. 


\section{Conclusion}

This study focused on the use of viscoelastic surfactants at low pressure gradient to investigate the effect of selective retardation between different permeability cores. It was shown that selective retardation of the flow in high permeability strata at application pressure gradient $(<1.0 \mathrm{bar} /$ $\mathrm{m}$ ) is possible. It has been experimentally proven that a substantial reduction in the difference in flow rate can be achieved between cores of varying permeability thereby creating a more uniform flow profile in a heterogeneous reservoir. Sweep efficiency is increased up to $16 \%$ while remaining in the low pressure gradient regime. Also a clear transition between Newtonian and non-Newtonian behavior has been observed as the pressure gradient increases.

The onset and magnitude of the selective viscosifying effect can be controlled by altering additive concentration. Increasing the equimolar concentration of $\mathrm{CTAB}$ and $\mathrm{NaSal}$ in brine leads to a greater enhancement of the viscosity and a decrease in the critical flow velocity at which non-Newtonian behavior and selective viscosifying set in. This implies it is possible to tailor the VES solution to meet specific reservoir conditions to overcome early water breakthrough.

These results are based on one phase experiments where there is no interaction with hydrocarbons. Literature tells us that worm-like micelles disintegrate when in contact with hydrocarbons; however, this only occurs at the oil/VES. A viscosity increase is preferable in low oil saturated regions where oil has already been recovered, so there would be little oil/VES contact.

Open Access This article is distributed under the terms of the Creative Commons Attribution 4.0 International License (http:// creativecommons.org/licenses/by/4.0/), which permits unrestricted use, distribution, and reproduction in any medium, provided you give appropriate credit to the original author(s) and the source, provide a link to the Creative Commons license, and indicate if changes were made.

\section{References}

Al-Mjeni M, Arora S, Cherukupalli P, van Wunnik J, Edwards J, Felber BJ, Gurpinar O, Hirisaki GJ, Miller CA, Jackson C, Kristensen MR, Lim F, Ramamoorthy R (2011) Has the time come for EOR? Oilfield Rev Winter 22(4):16-37

AlSofi AM, LaForce TR, Blunt MJ (2009) Sweep impairment due to polymer shear thinning. In: SPE Middle East Oil and Gas Show and Conference, SPE-120321-MS

Bear J (1972) Dynamics of fluids in porous media. American Elsevier, New York

Degré G, Morvan M (2012) Viscosifying surfactant technology for chemical EOR: a reservoir case. In: SPE EOR Conference at Oil and Gas West Asia, SPE-154675-MS
Delshad M, Kim DH, Magbagbeola OA, Huh C, Pope GA, Tarahhom F (2008) Mechanistic interpretation and utilization of viscoelastic behavior of polymer solutions for improved polymer-flood efficiency. In: SPE Symposium on Improved Oil Recovery, SPE113620-MS

Ezrahi S, Tuval E, Aserin A (2007) Properties, main applications and perspectives of worm micelles. Adv Colloid Interface Sci 128-130:77-102

Golombok M, van der Wijst R (2013) Permeability thickening fluids for improved secondary oil recovery. J Pet Sci Eng 110:22-26

Hartmann V, Cressely R (1996) Influence of sodium salicylate on the rheological behavior of an aqueous CTAB solution. Colloids Surf A 121(2-3):151-162

Hartmann V, Cressely R (1997) Simple salts effects on the characteristics of the shear thickening exhibited by an aqueous micellar solution of CTAB/NaSal. EPL 40:691-696

Hu Y, Wang Q, Jamieson AM (1994) Elongational flow behavior of cetyltrimethylammonium bromide/sodium salicylate surfactant solutions. J Phys Chem 98:8555-8559

Jones WM (1980) Polymer additives in reservoir flooding for oil recovery: Shear-thinning or shear-thickening? J Phys D Appl Phys 13:L87-L88

Moss GR, Rothstein JP (2009) Flow of wormlike micelle solutions through a periodic array of cylinders. J Non-Newton Fluid Mech 165:1-13

Reuvers N, Golombok M (2008) Shear rate and permeability in water flooding. J Transp Porous Med 79(2):249-253

Reuvers N, Golombok M (2009) Parameters for assessing oil reservoir water flooding additives. J Fluids Eng 131(3):031302-1-031302-6

Rojas MR, Müller AJ, Sáez AE (2008) Shear rheology and porous media flow of wormlike micelle solutions formed by mixtures of surfactants of opposite charge. J Colloid Interface Sci 326:221-226

Rojas MR, Müller AJ, Sáez AE (2009) Effect of ionic environment on the rheology of wormlike micelle solutions of mixtures of surfactants with opposite charge. J Colloid Interface Sci 342:103-109

Silva JAK, Smith MM, Munakata-Marr J, McCraf JE (2012) The effect of system variables on in-situ sweep-efficiency improvement via viscosity modification. J Contam Hydrol 136-137:117-130

Smeets M, Golombok M (2010) Application of shear induced structure materials for brine flooding in sandstone oil reservoirs. J Pet Sci Eng 72:270-276

Spain D, Troost S, Golombok M (2009) Shear induced structure additives and nonlinear pressure drop effects in permeable flow. J Colloid Interface Sci 338:261-265

Stavland A, Jonsbraten HC, Lohne A (2010) Polymer flooding-flow properties in porous media versus rheological parameters. In: SPE EUROPEC/EAGE Conference and Exhibition Barcelona, SPE 131103

Vasudevan M, Shen A, Khomami B, Sureshkumar R (2008) Selfsimilar shear thickening behavior in $\mathrm{CTAB} / \mathrm{NaSal}$ surfactant solutions. J Rheol 52:527-550

Vasudevan M, Buse E, Lu D, Krishna H, Kalyanaraman R, Shen AQ, Khomami B, Sureshkumar R (2010) Irreversible nanogel formation in surfactant solutions by microporous flow. Nat Mater 9:436-441

Wei B, Romero-Zerón L, Rodrigue D (2014) Oil displacement mechanisms of viscoelastic polymers in enhanced oil recovery (EOR): a review. J Pet Explor Prod Technol 4:113-121 